ISSN 1696-0300

\title{
3C@CTDI - COLABORAÇÃO, CONTRIBUIÇÃO E COMUNIDADE EM CTDI
}

\author{
Cândida Silva, Lino Oliveira, Milena Carvalho, Susana Martins \\ Escola Superior de Estudos Industriais e de Gestão (ESEIG)
}

RESUMEN: Los profesores de la licenciatura en Ciências e Tecnologias da Documentação e Informação (CTDI) se preparan para sacar partido de las herramientas Web 2.0 como un complemento de su actividad lectiva.

En este contexto, se presenta el Grupo de Investigación PIGeCo que pretende, por un lado, implementar la utilización de herramientas Web 2.0 de tal forma que se pueda conseguir ciertas premisas que actualmente orientan la nueva generación web (colaboración, contribución, comunidad), aplicandolas à la actividad lectiva e, por otro lado, el estímulo de la producción científica de los profesores y académica de los alumnos, así como su posterior análisis.

Se ha hecho una valoración de los proyectos en curso y se discuten las expectativas esperadas presentado un análisis de las perspectivas y ambiciones futuras del grupo.

PALABRAS CLAVE: Enseñanza distribuída, ambientes de aprendizaje colaborativos, e/b-learning, Web 2.0, sistemas de gestión de contenidos, blogs, wikis, tagging, social bookmarking, social networking, producción científica.

ABSTRACT: Teachers of the Ciências e Tecnologias da Documentação e Informação (CTDI) degree are preparing to take advantage of web 2.0 tools, using them as a complement of their activity.

PIGeCo, a research group recently created, is presented as a way to implement the web 2.0 tools, so that these teachers can reach the premises that nowadays rule the new web generation (collaboration, contribution, community), applying them to their teaching activity. They also intend to stimulate teacher's scientific production and student's academic work.

A state of the art of PIGeCo's projects is presented and expectations are discussed.The group also presents their perspectives and future ambitions..

KEYWORDS: Distributed teaching, collaborative learning environments, e/b-learning, Web 2.0, content management systems, blogs, wikis, tagging, social bookmarking, social networking, scientific production.

\section{INTRODUÇÃO}

A utilização das Tecnologias de Informação e Comunicação (TIC) nas metodologias de ensino/aprendizagem nas Instituições de Ensino Superior (IES) entrou nos hábitos de muitos docentes e estudantes e tem sido incrementada com a adopção de novas práticas devidas à adequação dos cursos ao Processo de Bolonha. 
A disponibilização dos conteúdos é uma faceta muito importante desta estratégia. Ao longo do tempo, o percurso seguido tem abordado diversas técnicas, desde repositórios de documentos num servidor ou em portais da IES, até sítios web de apoio às disciplinas, muitas vezes em domínios exteriores às IES.

Estas técnicas de disponibilização de conteúdos são frequentemente complementadas com métodos de interacção assíncrona (correio electrónico) e síncrona (instant messaging), estabelecendo uma relação directa com o aluno.

Diferentes técnicas têm vindo a generalizar-se nas metodologias aplicadas, sobretudo as derivadas do conceito de e-learning. Assim, surgiram as plataformas de ensino à distância.

Estas plataformas, das quais o Moodle é porventura a mais utilizada, permitem a disponibilização de conteúdos de modo semelhante ao conseguido com o sítio web da disciplina, mas possibilita a utilização de novas ferramentas no processo ensino/aprendizagem, não só ao nível da interacção assíncrona (notícias, fóruns de discussão, sindicância, etc.) e síncrona (chat) com o aluno, mas também na sua avaliação (publicação e recepção agendada de trabalhos, testes de avaliação online, inquéritos).

Apesar de todas estas técnicas, tem-se verificado que o envolvimento dos estudantes não é o mais desejado, sobretudo dos menos tecnologicamente motivados. Constata-se também que, apesar das técnicas funcionarem no âmbito de uma disciplina, não existe um modo fácil de desenvolvimento de dinâmicas interdisciplinares.

Impulsionada pela massificação do acesso de banda larga, uma (r)evolução está presentemente em curso que tem alterado a maneira como nos relacionamos com a Internet - a Web 2.0. Mais do que uma revolução tecnológica, assiste-se a uma evolução da maneira como se utilizam as tecnologias que já existem desde o início da Internet.

A explosão de popularidade desta nova variante da Web deve-se, fundamentalmente, aos seguintes factores:

- Banalização e democratização do acesso à Internet devido à maior disponibilização de banda larga a preços atractivos;

- Facilidade de utilização da Internet e consciência dos utilizadores do seu potencial; 
- Facilidade de utilização das ferramentas de criação de conteúdos com aplicações gratuitas baseadas na Web, logo disponíveis em qualquer lugar e em diversas plataformas de hardware, devido ao aparecimento de algumas tecnologias inovadoras como sejam $\mathrm{AJAX}^{1}$ e Flex $^{2}$, acesso simplificado a bases de dados através de Javascipt, Java ou Flash, a linguagem $\mathrm{XML}^{3}$ e os agregadores RSS ${ }^{4}$.

Na prática, isto leva a que a nova versão da Web seja caracterizada por

- Foco nos conteúdos;

- Publicação independente de conteúdos criados pelo utilizador;

- Efeitos de rede devidos a uma arquitectura baseada na participação;

- Socialware ou inteligência colectiva de utilizadores como resultado da contribuição e partilhas de experiências entre utilizadores com interesses comuns.

O sucesso de sítios web como Blogger ${ }^{5}$, Wikipedia $^{6}$, Hi5 $^{7}$, Flickr $^{8}$ ou YouTube ${ }^{9}$ permite verificar que as pessoas, sobretudo as incluídas na faixa etária dos estudantes do ensino superior, sentem agora maior facilidade e à-vontade na gestão de conteúdos na Web, usando ferramentas simples, intuitivas e disponíveis para todos.

Isto permite sustentar a ideia que a utilização de aplicações Web 2.0 no Ensino poderá trazer benefícios assinaláveis:

- Maior facilidade de comunicação e diálogo do professor com os seus estudantes, num meio em que eles se sentem à-vontade e onde lhes é fácil exprimirem-se sem quaisquer constrangimentos;

- Despertar nos estudantes o entusiasmo pela escrita, formando hábitos de construção de opinião e submissão dos textos à análise dos outros através do debate, funcionando como uma espécie de peer review;

\footnotetext{
${ }^{1}$ Asynchronous JavaScript and XML

${ }^{2}$ http://www.adobe.com/products/flex

${ }^{3}$ Extensible Markup Language

${ }^{4}$ Really Simple Syndication

${ }^{5}$ http://www.blogger.com

${ }^{6}$ http://www.wikipedia.org

${ }^{7}$ http://www.hi5.com

${ }^{8}$ http://www.flickr.com

${ }^{9}$ http://www.youtube.com
} 
- Fomentar o trabalho colaborativo que, através da pesquisa colectiva, poderá aumentar o interesse dos estudantes pelas matérias tratadas;

- A intervenção activa e participada dos estudantes nas actividades lectivas fomenta a autoconfiança.

O ensino de qualidade não se sustenta, apenas, da actividade lectiva. Tem que haver um aporte científico-tecnológico que possibilite ao docente a constante actualização, através da investigação, que se apresenta como pilar do ensino.

As actividades de investigação de carácter científico-tecnológico deverão originar artigos e outro tipo de publicações científicas. Aliás, é ponto assente que, independentemente da sua forma, a literatura científica surge como um reflexo da actividade levada a cabo pelos investigadores.

O estudo dessa actividade é uma modalidade relativamente recente. Leydesdorf (1995) assume que os estudos da Ciência se desenvolvem de maneira interdisciplinar com as próprias revistas, com as sociedades de peritos, sociedades científicas e departamentos de estabelecimentos do Ensino Superior.

Tradicionalmente os estudos Cienciométricos são classificados em duas categorias:

- Indicadores de actividade - que proporcionam dados sobre o volume e impacto das actividades de investigação; assume-se separações disciplinares, temáticas e institucionais;

Indicadores de relação - onde se identificam laços e interacções entre investigadores e áreas temáticas de modo a que fiquem (d)escritos os conteúdos das actividades e sua evolução; estudam fronteiras instáveis e permeáveis entre as diferentes áreas temáticas.

Estas duas tipologias remetem-nos para dois modelos do desenvolvimento científico e técnico.

Por um lado temos um modelo que assume e encara a Ciência como uma actividade produtiva normal, cujas fronteiras sofrem variações mas apenas a longo prazo. Neste modelo, as variáveis mais importantes são os inputs e os outputs, proporcionando a medição da produção e do impacto bem como a identificação das relações entre esses mesmos inputs e outputs considerando, no entanto, que a investigação científica e técnica baseia a sua eficácia nos múltiplos laços que se criam entre as diversas especialidades e áreas temáticas cujas fronteiras são variáveis e flutuantes ao longo do tempo. 
Por outro lado, temos um modelo encarado como um relacionador onde se identificam as várias comunidades científicas como uma consequência do papel e das estratégias levadas a cabo pelos vários actores presentes no contexto científico. Neste modelo, as relações entre cientistas e especialistas são privilegiadas e analisadas, tal como as áreas temáticas de investigação e as transformações que estas sofrem.

De facto, a publicação vai permitir um controlo institucionalizado que conduz a que o conhecimento seja:

- Partilhado e assumido pela comunidade;

- Mais fiável e disponível após superar as criticas mais exigentes da comunidade científica.

De notar no entanto que a ausência de resultados científicos não pode ser sinónimo de ausência de actividade científica, pois nem sempre esta conduz a resultados (satisfatórios). No entanto, em termos bibliométricos, para identificarmos os agentes científicos efectivos ${ }^{10}$, é condição sine qua non haver resultados científicos. No entanto, nem todos os agentes científicos são efectivos em todo o seu percurso como tal e, como referido anteriormente, essa falta de resultados não implica, obrigatoriamente, uma passividade científica, uma vez que os agentes científicos efectivos são, segundo Maltrás (2003), apenas um subconjunto do total de agentes científicos, pois existem, também, os agentes científicos potenciais ${ }^{11}$.

Tendo em conta tudo o que anteriormente foi referido, é possível afirmar que a Cienciometria estuda os aspectos quantitativos da ciência através da utilização de técnicas métricas de avaliação da Ciência, recorrendo, a indicadores bibliométricos e socio-económicos. Este tipo de análise estuda a Ciência como uma actividade económica, comparando políticas de investigação desenvolvidas e empregues por diferentes instituições bem como os seus resultados.

\section{DIAGNÓSTICO}

Para alguns docentes do curso de CTDI, sobretudo para os do $1^{\circ}$ ano, tornou-se notório que, para grande parte dos estudantes a motivação era diminuta. Apresentavam-se como utilizadores básicos da Internet e apenas alguns iam além

\footnotetext{
${ }^{10}$ Agentes científicos efectivos são aqueles que produzem resultados científicos

11 Agentes científicos potenciais são aqueles que, por algum motivo, se encontram temporariamente afastados da investigação e que se encontram dedicados a outras actividades.
} 
disso. Não traziam consigo hábitos de investigação e de discussão de assuntos e em ambiente de aula, o papel de aluno receptor passivo era assumido e desempenhado na totalidade, sendo que nos momentos em que a participação activa era solicitada, a adesão era diminuta.

Atendendo a este cenário adoptou-se a postura de incentivar, desde o $1^{\circ}$ Semestre do $1^{\circ}$ ano, os estudantes a pesquisar na web conteúdos relacionados com as matérias leccionadas, de modo a complementarem a bibliografia fornecida pelos docentes, sendo igualmente incentivados a tomar contacto com ferramentas de publicação na web. Alguns dos temas seriam também alvo de discussão em aula.

Apesar desta metodologia, foi constatado que, sempre que algum trabalho de investigação era desenvolvido, a grande maioria acabava por cair na tentação do copy+paste, o que para o estudante implicava ou a reprovação à disciplina ou a entrega de novo trabalho e para o docente representava um aumento da carga de trabalho.

Em paralelo a esta situação, o hábito de preparação e disponibilização de conteúdos digitais por parte dos docentes do curso verificava-se, apenas, junto dos docentes da área das Tecnologias, o que, restringia a utilização de ferramentas na Web a essa área. Docentes de outras áreas tentavam minimizar essa desvantagem através do envio, por e-mail, de textos de apoio e material complementar mas, essa metodologia apresentava-se sem hipótese de feedback imediato. Afinal, trata-se de uma metodologia assíncrona.

A falta de uniformidade manteve-se durante algum tempo, sustentada pela ausência de uma plataforma institucional que permitisse/possibilitasse e motivasse todos os docentes no sentido da disponibilização on-line e de forma dinâmica de material lectivo.

Em 2005 foi inaugurado o portal eu.ipp.pt onde já era possível disponibilizar aos alunos, num repositório digital incorporado a cada disciplina, material que o docente considerasse útil para as suas disciplinas. O portal não tem tido, no entanto, muita adesão por parte dos professores e dos estudantes.

Com a implementação da Declaração de Bolonha na ESEIG (em 2006/2007) e a natural evolução do curso e a experiência adquirida dos docentes, o curso de CTDI sofreu um processo de adequação, tendo-se aproveitado este período de mudança para implementar uma série de alterações, também ao nível da metodologia do ensino. 
Assim sendo, os estudantes que, embora paulatinamente e no decorrer do curso, vinham sendo habituados a consultar documentação disponibilizada on-line, viram essa estratégia alargar-se a disciplinas de outras áreas científicas. Nesta altura as ferramentas já eram amplamente usadas por alguns docentes do curso, embora a sua utilização não fosse homogénea - variavam entre páginas pessoais dos docentes, a plataforma de e-learning Moodle ou portal eu.ipp.pt.

Os docentes acabaram por constatar uma evolução na postura dos estudantes perante as tecnologias e a investigação, sendo que alguns já utilizam, a título pessoal, ferramentas da nova geração web - Web 2.0 ou Web social - como o Hi5 ou o MySpace.

Com a crescente utilização da plataforma Moodle, sentiu-se a necessidade de facultar a evolução na utilização da Internet e de trazer alguns destes hábitos dos estudantes para o ambiente académico, aproveitando o facto de neste ano lectivo, termos um grupo muito bom de estudantes, tecnologicamente motivados e aptos na utilização de diversas ferramentas de publicação.

Se um aspecto a melhorar era a dinâmica docente/discente, outro era aumentar a produção científica da ESEIG e em particular do curso de CTDI (Figura 1).

A análise da produção científica baseada em indicadores bibliométricos não é alheia à sociedade e a toda a actividade social. De facto a sociedade influencia o curso da Ciência. Assim, os indicadores bibliométricos devem, também eles, ser integrados, analisados e interpretados à luz de outro tipo de indicadores, os indicadores socio-económicos. Estes, permitem-nos interpretar os resultados e estabelecer relações das investigações com os dados que influenciam o seu desenvolvimento (Recursos Humanos e Recursos Financeiros).

A premissa inerente à importância dos indicadores socio-económicos é a seguinte: as condicionantes de qualquer investigação científica prendem-se com os recursos humanos e económicos, i.e., um investigador, grupo ou comunidade de investigadores será mais ou menos produtivo em função dos recursos humanos e económicos disponíveis.

Temos a consciência de que o motor da produção científica é a investigação. Sabemos no entanto que, no Ensino Superior Politécnico, por diversas razões (cortes orçamentais da tutela; aumento da carga de trabalho extra-lectiva que os docentes assumem), não existem grandes incentivos institucionais para se fazer investigação. Também, não há o hábito de fazer investigação ad-hoc e com isso escrever artigos. É urgente aumentar a produção científica. 
Figura 1 - Produção científica ESEIG 2004 (dados do Anuário Científico do IPP 2004)

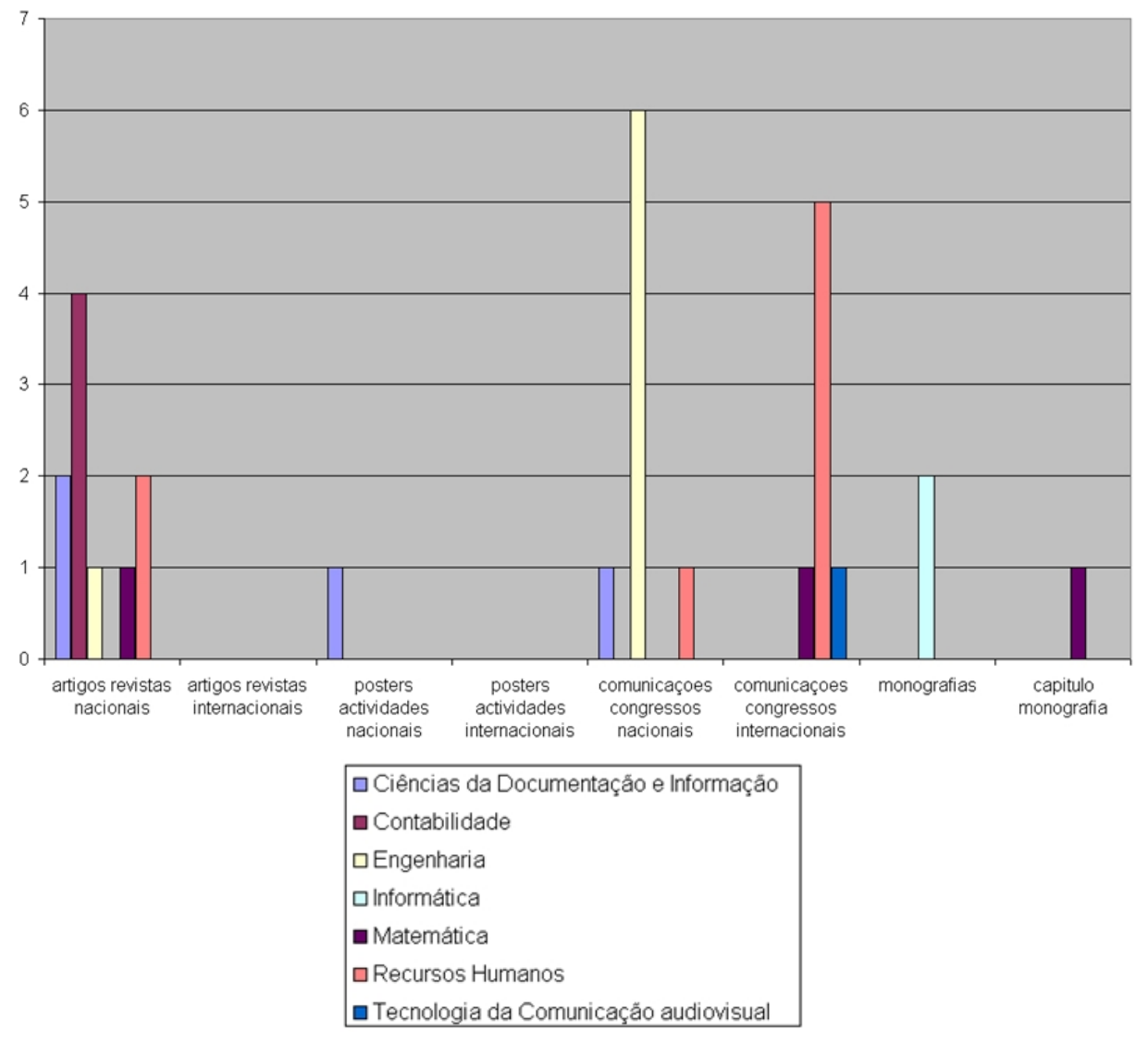

\section{METODOLOGIA}

Este conjunto de problemas e oportunidades vêm sendo sentidas e discutidas entre um grupo multidisciplinar de docentes do curso de CTDI. Neste seguimento, foram surgindo várias ideias de projectos, trabalhos e iniciativas que podiam ser levadas a cabo no âmbito do referido curso. Estes brainstorms foram tomando corpo e desta forma surgiu o projecto PIGeCo - Plataforma Integrada de Gestão de Conteúdos.

O principal objectivo é dinamizar o curso e a ESEIG de modo a permitir o desenvolvimento de investigação e discussão de temas que fomentem a produção científica. 
Por considerar que a actividade de investigação é essencial ao saudável crescimento e afirmação do curso de CTDI não só a nível profissional mas também a nível académico, o Grupo PIGeCo, sugeriu à Direç̧ão da ESEIG a criação de um Observatório de Investigação e Desenvolvimento da ESEIG - o ObIDe. Com a criação do Observatório pretendemos envolver diferentes áreas do curso, com o intuito de proceder à análise das diversas actividades de I\&D, da produção cientifica nos diversos campos abrangidos pela ESEIG, proceder à sua avaliação, permitindo a caracterização de actuações, indivíduos e grupos que desenvolvam esse tipo de acções na instituição.

Assim, propôs-se a criação de um projecto interdisciplinar integrador de todas as disciplinas do curso de CTDI, a partir do qual seja possível criar ferramentas de apoio às metodologias de ensino/aprendizagem e de divulgação da produção académica dos alunos e científica dos docentes.

Neste projecto estavam identificados alguns objectivos específicos, a saber:

- A transversalidade dos projectos sendo que todas as disciplinas deverão contribuir com trabalhos preparatórios e de manutenção, quer de conteúdos quer de estrutura;

- A dinamização do laboratório de CTDI, conjuntamente com a implementação da plataforma PIGeCo, permitirá criar as condições para a prestação de serviços;

- Desenvolvimento de iniciativas que possibilitem estender o âmbito de todo o projecto a toda a comunidade ESEIG.

Com o decorrer do tempo, foram surgindo outras ideias e necessidades, nomeadamente aumentar o nosso contributo e relacionamento com a comunidade empresarial, dando maior visibilidade ao curso e à ESEIG, que levaram à inevitável evolução do projecto para o Grupo de Investigação PIGeCo - Projectos Integrados de Gestão de Conteúdos.

Assim, as propostas de projectos são:

\section{Repositório digital}

Consiste no desenvolvimento de um repositório digital onde serão mantidos os documentos do curso, implementado numa ferramenta Open Access: CDS Invenio $^{12}$ ou DSpace ${ }^{13}$. Além da implementação do repositório também é nosso

\footnotetext{
${ }^{12}$ http://cdsware.cern.ch/invenio/index.html

${ }^{13}$ http://www.dspace.org
} 
objectivo uniformizar todos os documentos utilizados pelo curso, pela criação de templates para o efeito.

Pretende-se, por um lado, centralizar toda a documentação produzida pelo curso e por outro dar uma contribuição real à comunidade com a nossa experiência educativa disponibilizando em Open Access estes documentos.

\section{Magazine electrónico}

Este projecto visa a criação numa ferramenta Open Access de divulgação da produção académica dos alunos e científica dos docentes, com peer review.

A equipa de revisores será constituída por professores da ESEIG e por professores e investigadores de outras instituições.

A e-zine possibilitará a realização de discussões on-line sobre os trabalhos publicados, direccionando-as para uma plataforma de blogging.

\section{Servidor de blogues}

Este servidor permitirá a dinamização das discussões associadas aos artigos publicados no e-zine ou no âmbito das disciplinas do curso; deverá ser implementado em Wordpress $\mathrm{MU}^{14}$.

\section{Teaching 2.0}

Massificar a utilização da metodologia de ensino b-learning por todas as disciplinas do curso de CTDI, tirando partido de algumas das ferramentas Web 2.0. Como consequência, alargar a experiência a todos os cursos da ESEIG.

Desenvolver acções de formação para docentes na utilização de ferramentas Web 2.0 e de sensibilização para a forma como estas podem inovar as suas aulas e motivar a participação dos alunos.

\section{ObiDe}

O ObIDe foi criado com o intuito de proceder à análise das diversas actividades de I\&D, da produção cientifica nos diversos campos abrangidos pela ESEIG, proceder à sua avaliação, permitindo a caracterização de actuações, indivíduos e grupos que desenvolvam esse tipo de acções na instituição.

Com o ObIDe pretendemos proceder à:

${ }^{14}$ http://pt.wordpress.com/ 
- Descrição e análise o panorama da I\&D na ESEIG, atendendo a indicadores socio-económicos e bibliométricos;

- Avaliação da produção científica com base nos níveis de produção, impacto, visibilidade, colaboração entre outros;

- Estudo da estrutura e dinâmica dos investigadores nas diversas áreas constituintes da ESEIG;

- Promoção um melhor acesso à produção científica através do desenvolvimento de produtos de valor acrescentado, eventualmente, em colaboração com outros grupos de trabalho.

Através de várias acções como:

- Estudo das actividades de I\&D da ESEIG

- Estabelecimento de comparações internas e externas

- Identificação do posicionamento da produção científica por área temática

\section{RESULTADOS ESPERADOS}

O início deste projecto é recente, data de finais do $1^{\circ}$ semestre do actual ano lectivo. No entanto, notou-se um aumento do dinamismo de docentes e discentes do curso, por isso as expectativas são elevadas.

Neste momento estão já em desenvolvimento os seguintes projectos:

Plataforma de ensino à distância

Houve uma enorme utilização da plataforma Moodle por parte de diversos docentes do curso, sobretudo os de tecnologias. Espera-se que no próximo ano lectivo, todas as disciplinas do curso tenham completa cobertura no Moodle.

\section{Repositório digital}

Este trabalho está inserido no projecto de estágio de um aluno do curso de CTDI, que efectuou a selecção e instalação da ferramenta Open Access mais adequada à realidade do curso e da ESEIG. A escolha recaiu no CDS Invenio.

\section{Magazine electrónico}

Este trabalho está inserido no projecto de estágio de um aluno do curso de CTDI, onde se pretende a selecção e instalação da ferramenta Open Access mais 
adequada à realidade do curso e da ESEIG. A escolha recaiu no Open Journal System (OJS) ${ }^{15}$.

\section{ObiDe}

Está em desenvolvimento um questionário que será distribuído por todos os docentes da ESEIG, utilizando o QuestionPro ${ }^{16}$. A utilização desta ferramenta resulta da assinatura de um acordo de parceria entre a ESEIG e a QuestionPro empresa norte americana de desenvolvimento de software que criou uma solução fácil de usar e baseada na Web. Através do recurso a esta ferramenta, pretendemos agilizar a recolha de dados e o seu subsequente tratamento. Ser-nos-á possível criarmos e disponibilizarmos questionários on-line e por e-mail a em condições francamente favoráveis. De acordo com a QuestionPro, a ESEIG é a primeira instituição de ensino superior portuguesa a aceder à ferramenta através do QuestionPro University Sponsorship.

\section{Parcerias com o exterior}

Também já foram efectuados os primeiros contactos com uma biblioteca no sentido de estabelecer uma parceria para a criação de uma biblioteca digital da instituição.

\section{TRABALHO FUTURO}

Um dos objectivos do curso de CTDI é dotar os licenciados de competências nas diversas áreas da gestão de informação.

Conforme se pode constatar pela Figura 2, a evolução da Web aponta, desde já, para alguns caminhos:

- A utilização da semântica como base da gestão e pesquisa da informação on-line: Semantic Web;

- A mudança, cada vez mais acentuada, do paradigma da gestão de informação para a gestão do conhecimento;

- Novas experiências de navegação recorrendo a ambientes tridimensionais: Web 3D.

\footnotetext{
15 http://pkp.sfu.ca/ojs

16 http://www.questionpro.com/corporate-sponsorship/
} 
Neste contexto, procura-se que os profissionais de informação, e os licenciados de CTDI em particular, estejam aptos a acompanhar a mudança da melhor maneira, tirando partido das diversas ferramentas disponíveis.

Assim, num futuro próximo espera-se que os estudantes do curso de CTDI se familiarizem com algumas das seguintes aplicações:

- Google AdWords e Google AdSense ${ }^{17}$ para seleccionar a informação que melhor sirva os interesses num determinado contexto;

- Google Trends ${ }^{18}$ para analisar tendências em função das palavras que são mais pesquisadas;

- Google $\mathrm{CoOp}^{19}$ para personalizar ambientes de pesquisa que melhor se adaptem os cenários em causa;

Figura 2 - Evolução prevista para a Web

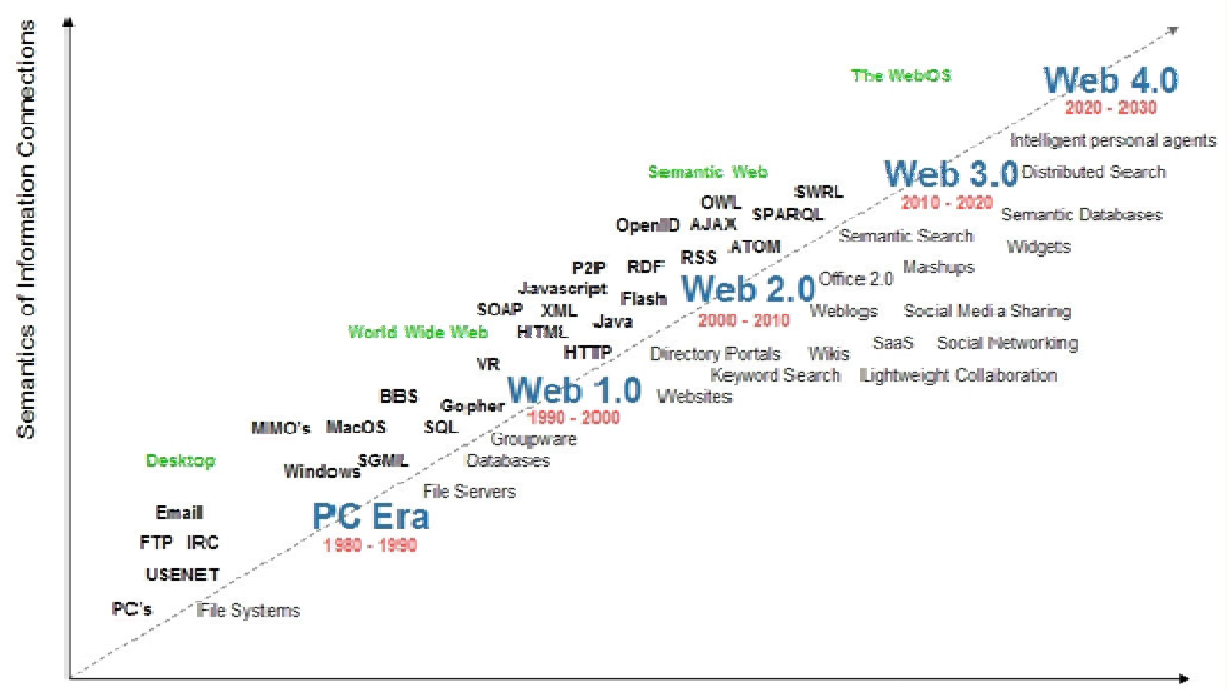

Semantics of Social Connections

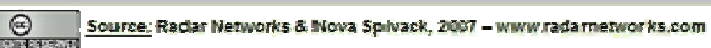

${ }^{17}$ http://www.google.com/adwords e http://www.google.com/adsense

$18 \mathrm{http} / / / \mathrm{www}$.google.com/trends

19 http://www.google.com/coop 
- Google Maps e Google Earth ${ }^{20}$ para integrar informação de contexto com informação geográfica;

- Mash-ups para integrar num único lugar, informação proveniente de diversas fontes;

- Second Life ${ }^{21}$ para participar em comunidades on-line tridimensionais.

Pretendemos ainda:

- Estimular o reconhecimento da investigação como actividade essencial à actividade lectiva;

- Incentivar os docentes à publicação de artigos;

- Promover o uso de metodologias de avaliação e análise da produção científica;

- Desenvolver uma base de dados dos trabalhos de investigação.

Pensamos que, deste modo, estamos a tornar os nossos estudantes aptos a responder aos desafios que se avizinham, num cenário de informação em constante evolução, preparados por docentes em constante actualização, assente numa cultura de investigação.

\section{REFERÊNCIAS}

Bayram, Özlem ; Atilgan, Doğan ; Arslantekin, Sacit (2006). "An Institutional Repository Initiative and Issues Concerning Metadata". En Guerrero-Bote, Vicente P., Eds. Proceedings I International Conference on Multidisciplinary Information Sciences And Technologies 1. Merida (Spain), InScit2006.

BERRY, Milles (2006) Knowledge management in education and the contribution of Virtual

Learning Environments. Computer Education 112, Spring 2006. Disponible en WWW: <URL: http://elgg.net/mberry/files/-1/4939/Knowledge\%20Management.pdf > e $<$ URL:http://elgg.net/mberry/weblog/11076.html>

Instituto Politécnico Do PORTO (2004). Anuário Científico. Porto : IPP.

LEYESDORFF, L. (1995). The challenge of Scientometrics: the development, measurement and self-organization of scientific communications. Netherlands: DSWO Press.

Malhotra, Y., Galletta, D. F. (2004). Building Systems That Users Want To Use. Communications of the ACM December 2004/Vol. 47, No. 12. Disponível em WWW: <URL:http://www.kmnetwork.com/ITUseCACM.pdf>

\footnotetext{
${ }^{20}$ http://www.google.com/maps e http://www.google.com/earth

${ }^{21}$ http://www.secondlife.com
} 
MALtRAs BARBA, B. (2003). Los indicadores bibliometricos: fundamentos y aplicación al analisis de la ciencia. Gijon : Trea.

Martins, S.; Oliveira, L.; CARVAlho, M.; Silva, C. (2006). Observatório de Investigação e Desenvolvimento - ESEIG, Proposta de Projecto. Vila do Conde.

MilAM, J. H., Jr. Knowledge Management for Higher Education. ERIC Digest. Disponível em WWW: <URL:http://www.ericdigests.org/2003-1/higher.htm>

Miller, P. - Web 2.0: Building the New Library. Ariadne Issue 45. Disponível em WWW: <URL: http://www.ariadne.ac.uk/issue45/miller>

MilleR, P. (2007). What is Web 2.0? Ideas, Technologies and Implications for Education. JISC Technology and Standards Watch, Fevereiro 2007. Disponível em WWW: <URL: http://www.jisc.ac.uk/media/documents/techwatch/tsw0701b.pdf>

OCDE (2003). Manual de Frascati: medicion de las actividades cientificas e tecnologicas : propuesta de norma pratica para encuestas de investigación y desarrollo experimental. Madrid: FECYT.

O'ReILly, T.. What Is Web 2.0 - Design Patterns and Business Models for the Next Generation of Software. O'Reilly Network. Disponível em WWW: <URL:http://www.oreillynet.com/pub/a/oreilly/tim/news/2005/09/30/what-is-web20.html>

Silva, C.; Oliveira, L.; Carvalho, M.; Martins, S. (2006). Plataforma Integrada de Gestão de Conteúdos - CTDI, Proposta de Projecto. Vila do Conde.

STUMPF, I. R. (1996). Passado e futuro das revistas científicas. In Ciência da Informação. Vol. 25, n. ${ }^{\circ}$ 3, 1996. Disponível em <URL:http://www.ibict.br/ cionline/include/ getdoc.php?id=846\&article=504\&mode=pdf $>$. Consultado em 26 de Junho 2005.

The New MEdia Consortium and EduCASE LEARning Iniciative (2007). The Horizon Report 2007 Edition. California, 2007. ISBN 0-975087-4-5. Disponível em WWW: <URL: http://www.nmc.org/pdf/2007_Horizon_Report.pdf>

TRAMUllas, J. (2005). Software libre para gestión de recursos de información digital. En Actas del Encuentro Internacional sobre Conocimiento Libre - II Conferencia Internacional de Software Libre. Mérida.

Ubon, A. Na; Kimblem, Ch. (2002). Knowledge Management in Online Distance Education. Networked Learning 2002. Disponível em WWW: <URL:http://www.cs.york.ac.uk/mis/docs/km_in_olde.pdf>

VAZ De CARVAlho, C. (org) (2006). e-learning e formação avançada - Casos de sucesso no Ensino Superior da Europa e América Latina. Edições Politema. Colecção Estudos. 
